\title{
Recent advances in the prevention and management of preterm birth
}

\author{
Min Yi Tan and Meekai To*
}

Address: Harris Birthright Unit, 3rd Floor, Golden Jubilee Wing, Denmark Hill, London SE5 9RS, UK

*Corresponding author: Meekai To (meekaito@nhs.net)

Fl000Prime Reports 2015, 7:40 (doi:10.12703/P7-40)

All FI000Prime Reports articles are distributed under the terms of the Creative Commons Attribution-Non Commercial License (http://creativecommons.org/licenses/by-nc/3.0/legalcode), which permits non-commercial use, distribution, and reproduction in any medium, provided the original work is properly cited.

The electronic version of this article is the complete one and can be found at: http://f $1000 . c o m / p r i m e /$ reports/m/7/40

\begin{abstract}
The management of preterm birth has seen major transformations in the last few decades with increasing interest worldwide, due to the impact of preterm birth on neonatal morbidity and mortality. The prevention strategies currently available for asymptomatic women at risk of preterm birth include progesterone, cervical cerclage and cervical pessary. Each approach has varying effects depending on the patient's prior history of preterm birth, cervical length and the presence of multiple gestations. There is a shift in the focus of antenatal treatment, with the use of prenatal magnesium sulphate and corticosteroids, to reduce neonatal intensive care admissions and longer-term disabilities associated with preterm birth, consequently relieving emotional and economical burden. This article provides an update on the recent advances in prevention and management approaches available for women at risk of preterm birth.
\end{abstract}

\section{Introduction}

Preterm birth is the leading cause of perinatal morbidity and mortality, and remains one of the biggest challenges in modern obstetrics [1]. It is estimated that more than one million children in the world die every year because of preterm birth [2]. The neonatal complications are closely related to the gestational age at delivery and include respiratory distress syndrome, intraventricular hemorrhage, periventricular leukomalacia, sepsis, and necrotizing enterocolitis. Severe long-term complications include cerebral palsy and neurodevelopmental delay $[3,4]$.

Preterm birth refers to delivery before 37 weeks' gestation, which occurs in 5-8\% of all pregnancies, but most mortality and morbidity relates to early preterm birth before 32 weeks, which occurs in about $1 \%$ of singletons and $9 \%$ of twin pregnancies $[5,6]$. Preterm birth can either be spontaneous, following premature labor with intact membranes, or preterm premature rupture of membranes (PPROM), or the consequence of iatrogenic delivery for maternal and/or fetal indications [7].
In this article, we will focus on recent advances in the prevention of spontaneous preterm birth and antenatal management strategies to reduce the neonatal complications of pregnancies delivering prematurely.

\section{Prevention of spontaneous preterm birth Cervical pessary}

Several retrospective studies showed promising results in the use of a cervical pessary for the reduction of spontaneous preterm birth in high-risk pregnancies [8-10]. Subsequent prospective randomized controlled trials (RCTs) provided conflicting results. The Pesario Cervical para Evitar Prematuridad (PECEP) study of cervical pessary vs. expectant management in 385 women with singleton pregnancies and sonographically defined short cervix ( $\leq 25 \mathrm{~mm}$ ) at $18-22$ weeks' gestation, reported that the pessary was associated with significant reduction in the rate of preterm birth $<34$ weeks ( $6 \%$ vs. $27 \%$; odds ratio (OR) $0.18,95 \%$ confidence interval (CI) $0.08-0.37$ ) [11]. Analysis of secondary outcomes also identified a decrease in respiratory distress syndrome (3\% vs. $12 \%$; OR $0.20,95 \% \mathrm{CI} 0.06-0.55$ ) and a reduction 
in neonates with a birth weight $<1500 \mathrm{~g}$ ( $5 \%$ vs. $14 \%$; OR $0.31,95 \%$ CI 0.13-0.72). Although the results appear promising, the generalizability of the results of this study has been questioned, due to the unexpectedly high rate of preterm birth in the control arm [12]. Another smaller trial of 108 singleton pregnancies with cervical length of $<25 \mathrm{~mm}$ at $20-24$ weeks' gestation did not demonstrate any significant differences in the rate of preterm birth $<34$ weeks $(9.4 \%$ vs. $5.5 \%, P=0.46)$ [13]. Neither study reported any serious adverse effects associated with the use of the pessary.

In multiple pregnancies, the use of cervical pessary was examined in the Pessaries in Multiple Pregnancy as a Prevention of Preterm Birth (ProTwin) trial, where 813 women with multiple pregnancies were randomized either to receive the pessary at $16-20$ weeks' gestation or to have routine care [14]. Overall, there was no difference between the two groups in the rate of preterm birth $(<28,32,37$ weeks' gestation) or poor perinatal outcome. However, in a subgroup analysis of women with a cervical length of $<38 \mathrm{~mm}$ (less than the $25^{\text {th }}$ percentile), the pessary significantly reduced the rate of very preterm birth $<28$ weeks (relative risk $[R R] 23,95 \%$ CI $0.06-0.87$ ) and preterm birth $<32$ weeks (RR 0.49 , 95\% CI 0.24-0.97), and composite poor perinatal outcome (RR $0.40,95 \%$ CI $0.19-0.83$ ). The results for the subgroup of women with a short cervix are consistent with those of the PECEP trial; nevertheless, these findings need to be replicated before definitive recommendations can be made.

\section{Progesterone}

Several studies have suggested that the prophylactic use of progesterone reduces the rates of preterm birth in women with a singleton pregnancy and a history of spontaneous preterm birth $[15,16]$, or a short cervix identified on transvaginal ultrasound at 19-25 weeks' gestation $[17,18]$. Both natural vaginal micronized preparation and synthetic intramuscular 17 alphahydroxyprogesterone (17-OHPC) have been investigated. The FDA approved progesterone use in 2011 and the American College of Obstetricians and Gynecologists (ACOG) and the Society for Maternal-Fetal Medicine recommended it in their 2012 treatment guidelines $[19,20]$. The algorithms created in these guidelines support the use of 17-OHPC but not vaginal progesterone in women with a prior spontaneous preterm birth. The reverse is true for women with a short cervix $(<20 \mathrm{~mm})$ where vaginal progesterone is the preferred option.

A Cochrane review published in 2013 summarized the effects of progesterone in women with a prior history of preterm birth based on 11 RCTs that included 1899 patients. Progesterone was associated with a reduced risk of preterm birth at $<34$ weeks (RR $0.31,95 \%$ CI $0.14-$ 0.69 ) and perinatal mortality (RR $0.50,95 \%$ CI $0.33-$ 0.75). There were also decreased rates of infants with a low birth weight $<2500 \mathrm{~g}$, necrotizing enterocolitis, neonatal death, and admission to a neonatal intensive care unit [21]. There were no observed disparities in outcomes when subgroup analyses were performed with different routes (intramuscular/vaginal/oral) and doses of progesterone administration, but the number of patients in each subgroup was small.

In asymptomatic singleton pregnancies with a sonographic short cervix $\leq 25 \mathrm{~mm}$, vaginal progesterone appears to be beneficial in reducing preterm birth and neonatal morbidity and mortality. In an individual patient data meta-analysis of five RCTs ( 775 women, 827 infants), the rate of early preterm birth at $<33$ weeks was significantly lower in women who received vaginal progesterone ( $12.4 \%$ vs. $22.0 \%$; RR 0.58 ; $95 \%$ CI $0.42-$ 0.80 ; numbers needed to treat [NNT] 11), the effect being evident regardless of a history of previous preterm birth [22]. Infants of treated women had significantly reduced the risk of respiratory distress syndrome $(6.1 \%$ vs. $12.5 \%$; RR $0.48 ; 95 \%$ CI $0.30-0.76)$, composite neonatal morbidity and mortality $(9.7 \%$ vs. $17.3 \%$; RR $0.57)$, and birth weight $<1500 \mathrm{~g}(8.8 \%$ vs. $16.5 \%$; RR $0.55)$. There was no increased risk of adverse maternal events or congenital anomalies between the treatment and placebo groups. Almost $90 \%$ of subjects in this meta-analysis were attributable to two trials $[17,18]$ that used different cervical length cut-offs of $<15 \mathrm{~mm}$ [17] and $10-20 \mathrm{~mm} \mathrm{[18]} \mathrm{and} \mathrm{doses} \mathrm{of} \mathrm{vaginal} \mathrm{progesterone}$ $200 \mathrm{mg} /$ day [17] and $90 \mathrm{mg} /$ day [18]. Despite these variations, the results from both studies were consistent with a $42 \%$ and $45 \%$ reduction in early preterm births.

There has only been one RCT that evaluated the effects of $17-O H P C$ vs. placebo in asymptomatic women with singleton pregnancies and a short cervix of $<30 \mathrm{~mm}$ [23]. There was no difference in the rate of preterm birth at $<37$ weeks $(25.1 \%$ vs. $24.2 \%$; RR 1.03 , 95\% CI $0.79-$ $1.35)$ or the rate of composite adverse neonatal outcome (7.0\% vs. 9.1\%; RR 0.77, 95\% CI 0.46-1.30).

In multiple pregnancies, several RCTs have reported the failure of both vaginal micronized progesterone and 17-OHPC to lower the rates of preterm birth in twins [24-27], and triplets [28,29]. A recently published individual participant data meta-analysis (13 trials; 3768 women/7536 infants) confirmed the lack of benefit in preventing preterm birth at $<34$ weeks when progestogens were used in unselected twin pregnancies 
(17-OHPC RR 1.1, 95\% CI 0.94-1.2; vaginal progesterone RR 0.97, 95\% CI 0.85-1.1) and also confirmed there were no differences in adverse perinatal outcome (17-OHPC RR 1.2, 95\% CI 0.87-1.5; vaginal progesterone RR 0.96; 95\% CI 0.83-1.1) [30]. However, in the subgroup of women with a cervical length of $\leq 25 \mathrm{~mm}$, vaginal progesterone was associated with a reduction in adverse perinatal outcome (15/56 vs. 22/60; RR 0.57; 95\% CI 0.47-0.70). The authors concluded that, although promising, these results should be interpreted with caution, due to the post hoc nature of the analysis and the small numbers involved. A recent RCT, comparing 17-OHPC to placebo in a 2:1 ratio, reported that there were no significant differences in the rates of preterm birth, but there were reductions in the rate of very low birth weight neonates $(7.6 \%$ vs. 14.3\%; RR 0.5; 95\% CI 0.3-0.9), composite neonatal morbidity ( $19.1 \%$ vs. $30.9 \%$; OR 0.53 ; $95 \%$ CI $0.31-$ $0.90)$, and respiratory distress syndrome $(14.4 \%$ vs. 23.4\%; OR 0.55; 95\% CI 0.31-0.98) [31].

The mechanism of preterm birth in multiple pregnancies is likely to be related to uterine distension, which appears to be unresponsive to progesterone unless there is already cervical shortening (which may be an early sign of the onset of parturition). Some authors have suggested that asymptomatic twin pregnancies may require increased doses of vaginal progesterone in order for it to be effective at reducing preterm birth in a similar way to singleton pregnancies. However, one RCT found that vaginal progesterone did not reduce preterm birth at either 200 or $400 \mathrm{mg}$ [32].

Recently, safety concerns have been raised about the use of 17-OHPC. In an RCT involving women with triplet pregnancies, the group receiving weekly injections of $250 \mathrm{mg}$ 17-OHPC experienced 13 mid-trimester fetal losses vs. none in the placebo group $(P<0.02)$ [29]. In another study of asymptomatic twin pregnancies in women with a short cervix, treatment with 17-OHPC was associated with a significant increase in the rate of preterm birth at $<32$ weeks $(29 \%$ vs. $12 \% ; P=0.007)$ [33]. Furthermore, in a recent meta-analysis, in the subgroup of women with a cervical length of $>25 \mathrm{~mm}$ treated with 17-OHPC there was a worrying trend towards increased adverse perinatal outcome (RR 2.1, 95\% CI 1.9-2.2) [30].

\section{Cervical cerclage vs. progesterone}

Cervical cerclage appears to be beneficial in reducing spontaneous preterm birth in high-risk groups (women with $>3$ preterm births and women with $>1$ preterm births with cervical length $<25 \mathrm{~mm}$ at $<24$ weeks) [34,35]. However, no RCTs have been performed that compare the relative efficacy of vaginal progesterone with cervical cerclage in high-risk women. An indirect patient metaanalysis suggested that both interventions are equally effective both in the reduction of preterm birth and in adverse perinatal outcomes in singleton pregnancies of women with prior preterm birth and cervical length $<25 \mathrm{~mm}$ in mid-trimester [36].

It is not known whether the effects of cerclage and progesterone are additive if used in combination. However, a secondary analysis of an RCT evaluating cerclage vs. expectant management for women with singleton pregnancies, prior spontaneous preterm birth and short cervix, found that the administration of 17-OHPC did not have an additional benefit to cerclage in reducing preterm birth, but actually increased the rates of miscarriage and perinatal mortality [37].

\section{Antenatal management strategies to reduce neonatal complications of preterm birth Antenatal corticosteroids}

Maternal administration of corticosteroids reduces the rates of respiratory distress syndrome, intraventricular hemorrhage and death in neonates born prematurely, and the maximum benefit occurs if the drug is given at $<7$ days from preterm birth [38]. Although the administration of a single course of corticosteroids is not associated with adverse effects on the mother or baby [39], the use of repeated courses is controversial.

A systematic review and meta-analysis on the use of multiple courses reported that such treatment was associated with improved neonatal respiratory function but also with adverse effects on brain function and fetal growth [40]. Similarly, an earlier Cochrane review reported that multiple courses of corticosteroids resulted in a reduction in birth weight in one trial of 1144 infants, and an increase in the number of small for gestational age babies in two trials with 602 infants [41]. However, a more recent Cochrane review, including 10 RCTs, reported that the treatment of women who remain at risk of preterm birth seven or more days after an initial course of prenatal corticosteroids with repeat dose(s), compared with no repeat corticosteroid treatment, reduced the risk of their infants experiencing the primary outcomes respiratory distress syndrome (RR 0.83, 95\% CI 0.75-0.91, eight trials, 3206 infants, NNT 17, 95\% CI 11 to 32 ) and serious infant outcome (RR $0.84,95 \%$ CI 0.75 to 0.94 , seven trials, 5094 infants, NNT 30, 95\% CI 19 to 79), without an effect on birth weight where outcomes were adjusted for gestational age. At early childhood follow-up, the primary outcomes (mortality, survival free of disability, serious outcome) and secondary growth assessments did not reveal any significant 
differences between those with and without repeated doses of antenatal corticosteroids [42]. The lack of longer-term benefits of multiple courses vs. a single course of steroids has been replicated in the recently reported MACS-5 study, where no difference in a primary outcome of death or neurodisability at 5 years of age was seen in any preterm gestational age category [43]. However, of potential concern, for infants born $\geq 37$ weeks gestation, there was a statistically significant increase in the risk of the primary outcome in multiple antenatal corticosteroid therapy: 48/213 (22.5\%) compared to $38 / 249(15.3 \%)$ in the single antenatal corticosteroid therapy; OR $=1.69$ 95\% CI: $1.04,2.77$; $P=0.037$. This difference was primarily driven by a fourfold increase in neurosensory disability, which in turn appears largely due to an increase in the need for visual aids. This should be interpreted with caution given that the gestational age windows were determined postrandomization, hence making it possible there were preexisting differences to account for the findings [43].

\section{Magnesium sulphate}

Magnesium sulphate $\left(\mathrm{MgSO}_{4}\right)$ is widely used for seizure prophylaxis in pre-eclampsia and the treatment of eclampsia but, when used as a tocolytic, appears to confer no clear benefit in prevention of preterm delivery or serious infant outcome, when compared with placebo or other tocolytics [44]. However, when used with the primary intention of neuroprotection, there appears to be a significant benefit over placebo. An association between mothers who received $\mathrm{MgSO}_{4}$ and a lower risk of cerebral palsy was first observed in a case control study in 1995 [45]. This finding was supported by five subsequent RCTs [46-50]. A meta-analysis of five RCTs (5235 infants) concluded that prenatal exposure to $\mathrm{MgSO}_{4}$ significantly reduced the rates of cerebral palsy of any severity (RR 0.70 , 95\% CI $0.55-0.89$ ) and moderate-severe cerebral palsy (RR 0.60, 95\% CI 0.430.84 ), without increased risk of mortality (RR $1.0195 \%$ CI 0.89-1.14) [51]. The number needed to treat to prevent one case of cerebral palsy among infants who survive until the age of 18-24 months was 46 (95\% CI 26-187) and 56 (95\% CI 34-164) in infants exposed to $\mathrm{MgSO}_{4}$ in utero before 30 weeks and between 32 and 34 weeks, respectively.

Another meta-analysis of six RCTs (4796 women and 5357 infants delivered before 34 weeks), reported a significant reduction in the risk of cerebral palsy (RR $0.69,95 \%$ CI $0.55-0.88)$, and substantial gross motor dysfunction (RR $0.60,95 \%$ CI $0.43-0.83$ ) with no difference in perinatal mortality [52]. The Cochrane review reported similar results, confirming the neuroprotective role of $\mathrm{MgSO}_{4}$ with a significant lower risk of cerebral palsy ( $3.4 \%$ vs. $5 \%$; RR $0.68,95 \%$ CI $0.54-0.87$; 6145 infants) and also substantial gross motor dysfunction (RR 0.61, 95\% CI 0.44-0.85; 5980 infants) [53]. These findings prompted professional bodies to issue recommendations in favor of using $\mathrm{MgSO}_{4}$ in anticipated early preterm birth [54-56]. However, the optimal gestation and dosage of $\mathrm{MgSO} 4$ for neuroprotection remain to be determined, as it was reported that many women ceased therapy due to these adverse effects ( $8 \%$ vs. 2.4\%; RR 3.26, 95\% CI 2.46-4.31) [53]. The previous RCTs used 4 or $6 \mathrm{~g}$, as loading dose, with some continuing with a maintenance dose of 1 or $2 \mathrm{~g} /$ hour.

More recently, the authors of one of the original RCTs of $\mathrm{MgSO} 4$ for neuroprotection in women at risk of delivery $<30$ weeks, reported on neurological, cognitive, behavioral, growth and functional outcomes in school age children (6-11 years) and found no benefit over placebo. These results may be unsurprising given that the original study did not show a reduction in cerebral palsy, although there was a reduction in gross motor dysfunction (3.4\% vs. 6.6\%; RR 0.51; 95\% CI, 0.29-0.91). Further data are required to be certain of these recent findings which, as the authors point out, may have been affected by sub-optimal follow-up rates (77\%) and low rates of gross motor dysfunction $(3.5 \%)$ in the placebo group [57].

\section{Conclusions}

Progesterone has been shown to reduce the risk of preterm birth both in low-risk women with a short cervix and high-risk women with a history of prior preterm birth. There is some evidence that progesterone may also improve perinatal outcomes, but this needs to be studied in larger RCTs. Progesterone does not have any clear benefit in unselected twin pregnancies, but its role in those women with a short cervix warrants further investigation. There is concern about the safety of 17 OHPC but no adverse effects from natural progesterone have been reported. The evidence for the use of the cervical pessary in singleton and twin pregnancies remains unclear, but further RCTs, particularly in women with short cervix, are warranted.

Maternal administration of corticosteroids reduces the rates of mortality and morbidity for neonates born prematurely. Although significant short-term benefits for the neonate have been seen with repeat courses compared with a single course, there appears to be less evidence that this translates to improved long-term outcomes. Whilst there is cumulative evidence for the neuroprotective role of $\mathrm{MgSO}_{4}$ in reducing the risk of moderate-severe cerebral palsy in early childhood, the long-term benefits remain to be proven. 
For all the therapies discussed, further studies addressing mechanisms of action, as well as those designed to determine the long-term outcome, are needed to help us understand the true risks and benefits of these interventions. Such data are now being reported for $\mathrm{MgSO}_{4}$ and repeated doses of antenatal steroids. In both circumstances, the evidence suggests that the long-term benefits may be limited.

\section{Abbreviations}

17-OHPC, 17 alpha-hydroxyprogesterone; $\mathrm{CI}$, confidence interval; NNT, numbers needed to treat; OR, odds ratio; PECEP, Pesario Cervical para Evitar Prematuridad; RCT, randomized controlled trial; $\mathrm{RR}$, relative risk.

\section{Disclosures}

The authors declare that they have no disclosures.

\section{References}

I. Centre for Maternal and Child Enquiries (CMACE): Perinatal Mortality 2008: United Kingdom. CMACE: London, 2010.

2. March of Dimes, PMNCH, Save the Children, WHO: Born Too Soon: The Global Action Report on Preterm Birth. Edited by CP Howson, MV Kinney and JE Lawn. World Health Organization. Geneva, 2012. http://apps.who.int/iris/bitstream// 0665/44864/I/ 978924 I503433_eng.pdf?ua= I

3. Stoll BJ, Hansen NI, Bell EF, Shankaran S, Laptook AR, Walsh MC, Hale EC, Newman NS, Schibler K, Carlo WA, Kennedy KA, Poindexter BB, Finer NN, Ehrenkranz RA, Duara S, Sánchez PJ, O'Shea TM, Goldberg RN, Van Meurs KP, Faix RG, Phelps DL, Frantz ID 3rd, Watterberg KL, Saha S, Das A, Higgins RD; Eunice Kennedy Shriver National Institute of Child Health and Human Development Neonatal Research Network: Neonatal outcomes of extremely preterm infants from the NICHD Neonatal Research Network. Pediatrics 2010, I26:443-56.

4. Moore T, Hennessy EM, Myles J, Johnson SJ, Draper ES, Costeloe KL, Marlow NI: Neurological and developmental outcome in extremely preterm children born in England in 1995 and 2006: the EPICure studies. BMJ 20I2, 345:e796I.

5. To MS, Fonseca EB, Molina FS, Cacho AM, Nicolaides KH: Maternal characteristics and cervical length in the prediction of spontaneous early preterm delivery in twins. Am J Obstet Gynecol 2006, 194:1360-5.

6. Schaaf J, Mol B, Abu-Hanna A, Ravelli A: Trends in preterm birth: singleton and multiple pregnancies in the Netherlands, 2000-2007. BJOG 20II, I I8:1 I96-204.

7. Goldenberg RL, Culhane JF, lams JD, Romero R: Epidemiology and causes of preterm birth. Lancet 2008, 371:75-84.

8. J Newcomer: Pessaries for the treatment of incompetent cervix and premature delivery. Obstet Gynecol Surv 2000, 55:443-8.

9. Arabin B, Halbesma JR, Vork F, Hübener M, Van-Eyck J: Is treatment with vaginal pessaries an option in patients with a sonographically detected short cervix. J of Perinatal Med 2003, 3 I: 122-33.

10. Acharya G, Eschler B, Grønberg M, Hentemann M, Ottersen T, Maltau JM: Noninvasive cerclage for the management of cervical incompetence: a prospective study. Archives of Gynecol and Obstet 2006, 273:283-7.

II. Goya M, Pratcorona L, Merced C, Rodo C, Valle L, Romero A, Juan M, Rodríguez A, Muñoz B, Santacruz B, Bello-Muñoz JC, Llurba E, Higueras T, Cabero L, Carreras E; Pesario Cervical para Evitar Prematuridad (PECEP) Trial Group: Cervical pessary in pregnant women with a short cervix (PECEP): an open-label randomised controlled trial. Lancet 20I2, 379:1800-6.

\section{FIOOOPrime}

12. Abdel-Aleem H, Shaaban OM, Abdel-Aleem MA: Cervical pessary for preventing preterm birth. Cochrane Database Syst Rev 2013, 5: CD007873.

13. Hui SYA, Chor CM, Lau TK, Lao TT, Leung TY: Cerclage pessary for preventing preterm birth in women with a singleton pregnancy and a short cervix at 20 to 24 weeks: a randomized controlled trial. Am J Perinatol 20I3, 30:283-8.

14. Liem S, Schuit E, Hegeman M, Bais J, de Boer K, Bloemenkamp K, Brons J, Duvekot H, Bijvank BN, BN, Franssen M, Gaugler I, de Graaf I, Oudijk M, Papatsonis D, Pernet P, Porath M, Scheepers L, Siddema M, Sporken J, Visser H, van Wijngaarden W, Woiski M, van Pampus M, Mol BW, Bekedam D: Cervical pessaries for prevention of preterm birth in women with a multiple pregnancy (ProTwin): a multicenter, open-label randomized controlled trial. Lancet 2013, 382:134|-9.

\section{FlOOOPrime
RECOMMENDED}

15. da Fonseca EB, Bittar RE, Carvalho MH, Zugaib M: Prophylactic administration of progesterone by vaginal suppository to reduce the incidence of spontaneous preterm birth in women at increased risk: a randomized placebo-controlled doubleblind study. Am J Obstet Gynecol 2003, 188:419-24.

16. Meis PJ, Klebanoff M, Thom E, Dombrowski MP, Sibai B, Moawad AH, Spong CY, Hauth JC, Miodovnik M, Varner MW, Leveno KJ, Caritis SN, lams JD, Wapner RJ, Conway D, O'Sullivan MJ, Carpenter M, Mercer B, Ramin SM, Thorp JM, Peaceman AM, Gabbe S; National Institute of Child Health and Human Development Maternal-Fetal Medicine Units Network: Prevention of recurrent preterm delivery by 17 alpha-hydroxyprogesterone caproate. N Engl J Med 2003, 348:2379-85.

\section{FlOOOPrime}

RECOMMENDED

17. Fonseca EB, Celik E, Parra M, Singh M, Nicolaides KH: Fetal Medicine Foundation Second Trimester Screening Group. Progesterone and the risk of preterm birth among women with a short cervix. N Engl J Med 2007, 357:462-9.

\section{FlOOOPrime}

\section{RECOMMENDED}

18. Hassan SS, Romero R, Vidyadhari D, Fusey S, Baxter JK, Khandelwal M, Vijayaraghavan J, Trivedi Y, Soma-Pillay P, Sambarey P, Dayal A, Potapov V, O'Brien J, Astakhov V, Yuzko O, Kinzler W, Dattel B, Sehdev H, Mazheika L, Manchulenko D, Gervasi MT, Sullivan L, Conde-Agudelo A, Phillips JA, Creasy GW; PREGNANT Trial: Vaginal progesterone reduces the rate of preterm birth in women with a sonographic short cervix: a multicenter, randomized, double-blind, placebo-controlled trial. Ultrasound Obstet Gynecol 201 I, 38:18-31.

\section{FlOOOPrime
RECOMMENDED}

19. Committee on Practice Bulletins - Obstetrics, The American College of Obstetricians and Gynecologists: Practice Bulletin No. 130: Prediction and prevention of preterm birth. Obstet Gynecol 2012, I20:964-73.

\section{FlOOOPrime}

RECOMMENDED

20. Society for Maternal-Fetal Medicine Publications Committee, with assistance of Vincenzo Berghella: Progesterone and preterm birth prevention: translating clinical trials data into clinical practice. Am J Obstet Gynecol 20I2, 206:376-86.

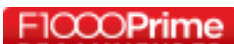
RECOMMENDED

2I. Dodd JM, Jones L, Flenady V, Cincotta R, Crowther CA: Prenatal administration of progesterone for preventing preterm birth 
in women considered to be at risk of preterm birth. Cochrane Database Syst Rev 2013, 7:CD004947.

\section{FIOOOPrime}

22. Romero R, Nicolaides K, Conde-Agudelo A, Tabor A, O'Brien JM, Cetingoz E, Da Fonseca E, Creasy GW, Klein K, Rode L, Soma-Pillay P, Fusey S, Cam C, Alfirevic Z, Hassan SS: Vaginal progesterone in women with an asymptomatic sonographic short cervix in the mid-trimester decreases preterm delivery and neonatal morbidity: a systematic review and metaanalysis of individual patient data. Am J Obstet Gynecol 2012, 206:I24.el-19.

\section{FlOOOPrime RECOMMENDED}

23. Grobman WA, Thom EA, Spong CY, lams JD, Saade GR, Mercer BM, Tita AT, Rouse DJ, Sorokin Y, Wapner RJ, Leveno KJ, Blackwell S, Esplin MS, Tolosa JE, Thorp JM Jr, Caritis SN, Van Dorsten JP; Eunice Kennedy Shriver National Institute of Child Health and Human Development Maternal-Fetal Medicine Units (MFMU) Network: 17 alpha-hydroxyprogesterone caproate to prevent prematurity in nulliparas with cervical length less than $\mathbf{3 0} \mathbf{~ m m}$. Am J Obstet Gynecol 20I2, 207:390.el-8.

\section{FIOOOPrime}

24. Norman JE, Mackenzie F, Owen P, Mactier H, Hanretty K, Cooper S, Calder A, Mires G, Danielian P, Sturgiss S, MacLennan G, Tydeman G, Thornton S, Martin B, Thornton JG, Neilson JP, Norrie J: Progesterone for the prevention of pre- term birth in twin pregnancy (STOPPIT): a randomised, double-blind, placebo-controlled study and meta-analysis. Lancet 2009, 373:2034-40.

\section{FlOOOPrime \\ RECOMMENDED}

25. Rouse DJ, Caritis SN, Peaceman AM, Sciscione A, Thom EA, Spong CY, Varner M, Malone F, lams JD, Mercer BM, Thorp J, Sorokin Y, Carpenter M, Lo J, Ramin S, Harper M, Anderson G; National Institute of Child Health and Human Development Maternal-Fetal Medicine Units Network: A trial of 17 alpha-hydroxyprogesterone caproate to prevent prematurity in twins. N EnglJ Med 2007, 357:454-6I.

\section{FlOOOPrime
RECOMMENDED}

26. Rode L, Klein K, Nicolaides KH, Krampl-Bettelheim E, Tabor A; PREDICT Group: Prevention of preterm delivery in twin gestations (PREDICT): a multicenter, randomized, placebocontrolled trial on the effect of vaginal micronized progesterone. Ultrasound Obstet \& Gynecol 20I I, 38:272-80.

27. Combs CA, Garite T, Maurel K, Das A: I7-hydroxyprogesterone caproate for twin pregnancy: a double-blind, randomized clinical trial. Am J Obstet Gynecol 20I I, 204:22 I.el-8.

28. Caritis SN, Rouse DJ, Peaceman AM, Sciscione A, Momirova V, Spong CY, lams JD, Wapner RJ, Varner M, Carpenter M, Lo J, Thorp J, Mercer BM, Sorokin Y, Harper M, Ramin S, Anderson G; Eunice Kennedy Shriver National Institute of Child Health and Human Development (NICHD), Maternal-Fetal Medicine Units Network (MFMU): Prevention of preterm birth in triplets using 17 alpha-hydroxyprogesterone caproate: a randomized controlled trial. Obstet Gynecol 2009, I 13:285-92.

29. Combs CA, Garite T, Maurel K, Das A, and Porto M: Failure of I7hydroxyprogesterone to reduce neonatal morbidity or prolong triplet pregnancy: a double-blind, randomized clinical trial. Am J Obstet Gynecol 2010, 203:248.el-248.e9.

\section{FlOOOPrime}

RECOMMENDED

30. Schuit E, Stock S, Rode L, Rouse DJ, Lim AC, Norman JE, Nassar A, Serra V, Combs C, Vayssiere C, Aboulghar M, Wood S, Cetingöz E, Briery C, Fonseca E, Worda K, Tabor A, Thom E, Caritis S, Awwad J, Usta I, Perales A, Meseguer I, Maurel K, Garite T, Aboulghar M, Amin Y, Ross S, Cam C, Karateke A, et al.: Effectiveness of progestogens to improve perinatal outcome in twin pregnancies: an individual participant data meta-analysis. BJOG 2014, I 22:27-37.

\section{FlOOOPrime
RECOMMENDED}

31. Awwad J, Usta IM, Ghazeeri G, Yacoub N, Succar J, Hayek S, Saasouh W, Nassar AH: A randomised controlled double-blind clinical trial of I7-hydroxyprogesterone caproate for the prevention of preterm birth in twin gestation (PROGESTWIN): evidence for reduced neonatal morbidity. BJOG 20I4, | 22:7|-9.

\section{FlOOOPrime}

\section{RECOMMENDED}

32. Serra V, Perales A, Meseguer J, Parrilla J, Lara C, Bellver J, Grifol R, Alcover I, Sala M, Martínez-Escoriza J, Pellicer A: Increased doses of vaginal progesterone for the prevention of preterm birth in twin pregnancies: a randomised controlled double-blind multicentre trial. BJOG 20I3, I20:50-7.

\section{FlOOOPrime
RECOMMENDED}

33. Senat MV, Porcher R, Winer $N$, Vayssière $C$, Deruelle $P$, Capelle $M$, Bretelle F, Perrotin F, Laurent Y, Connan L, Langer B, Mantel A, Azimi S, Rozenberg P; Groupe de Recherche en Obstétrique et Gynécologie: Prevention of preterm delivery by 17 alphahydroxyprogesterone caproate in asymptomatic twin pregnancies with a short cervix: a randomized controlled trial. Am J Obstet Gynecol 2013, 208:194.el-8.

\section{FlOOOPrime}

\section{RECOMMENDED}

34. MRC/RCOG. Working Party on Cervical Cerclage: Final report of the Medical Research Council/Royal College of Obstetricians and Gynaecologists multicentre randomized trial of cervical cerclage. BJOG 1993, 100:516-23.

35. Berghella V, Odibo AO, To MS, Rust OA, Althuisius SM: Cerclage for short cervix on ultrasonography: meta-analysis of trials using individual patient-level data. Obstet Gynecol 2005, 106: 181-9.

36. Conde-Agudelo A, Romero R, Nicolaides K, Chaiworapongsa T, O'Brien JM, Cetingoz E, da Fonseca E, Creasy G, Soma-Pillay P, Fusey S, Cam C, Alfirevic Z, Hassan SS: Vaginal progesterone versus cervical cerclage for the prevention of pre-term birth in women with a sonographic short cervix, previous preterm birth, and singleton gestation: a systematic review and indirect comparison meta-analysis. Am J Obstet Gynecol 2013, 208:42.el-I8.

37. Berghella V, Figueroa D, Szychowski JM, Owen J, Hankins GDV, lams JD, Sheffield JS, Perez-Delboy A, Wing DA, Guzman ER, for the Vaginal Ultrasound Trial Consortium: I 7- $\alpha$-Hydroxyprogesterone caproate for the prevention of preterm birth in women with prior preterm birth and a short cervical length. Am J Obstet Gynecol 2010, 202:35I.el-6.

\section{FlOOOPrime
RECOMMENDED}

38. Roberts D, Dalziel SR: Antenatal corticosteroids for accelerating fetal lung maturation for women at risk of preterm birth. Cochrane Database Syst Rev 2006, CD004454.

39. Dessens AB, Haas HS, Koppe JG: Twenty-year follow-up of antenatal corticosteroid treatment. Pediatrics 2000, I05:E77.

40. Aghajafari F, Murphy K, Willan A, Ohlsson A, Amankwah K, Matthews S, Hannah M: Multiple courses of antenatal corticosteroids: a systematic review and meta-analysis. Am J Obstet Gynecol 2001, I 85:1073-80.

4I. Crowther CA, Harding JE: Repeat doses of prenatal corticosteroids for women at risk of preterm birth for preventing neonatal respiratory disease. Cochrane Database Syst Rev 2007, CD003935.

42. Crowther CA, McKinlay CJ, Middleton P, Harding JE: Repeat doses of prenatal corticosteroids for women at risk of preterm 
birth for improving neonatal health outcomes. Cochrane Database Syst Rev 2011 , CD003935.

\section{FlOOOPrime}

43. Asztalos E, Willan A, Murphy K, Matthews S, Ohlsson A, Saigal S, Armson A, Kelly E, Delisle MF, Gafni A, Lee S, Sananes R, Rovet J, Guselle P, Amankwah K; MACS-5 Collaborative Group. Association between gestational age at birth, antenatal corticosteroids, and outcomes at 5 years: multiple courses of antenatal corticosteroids for preterm birth study at 5 years of age (MACS-5). BMC Pregnancy Childbirth 2014, 14:272.

\section{FlOOOPrime}

\section{RECOMMENDED}

44. Crowther CA, Brown J, McKinlay CJ, Middleton P: Magnesium sulphate for preventing preterm birth in threatened preterm labour. Cochrane Database Syst Rev 2014, CD00 1060.

45. Nelson KB, Grether JK: Can magnesium sulphate reduce the risk of cerebral palsy in very low birth weight infants? Pediatrics 1995, 95:263-9.

46. Mittendorf R, Dambrosia J, Pryde PG, Lee K, Gianopoulos JG, Besinger RE, Tomich PG: Association between the use of antenatal magnesium sulfate in preterm labor and adverse health outcomes in infants. Am J Obstet Gynecol 2002, I 86: I I I I-8.

47. Crowther CA, Hiller JE, Doyle LW, Haslam RR: Effect of magnesium sulfate given for neuroprotection before preterm birth: a randomized controlled trial. JAMA 2003, 290:2669-76.

FIOOOPrime

48. The Magpie Trial: a randomized trial comparing magnesium sulphate with placebo for pre-eclampsia. Outcome for children at 18 months. BJOG 2007, I | 4:289-99.

49. Marret S, Marpeau L, Zupan-Simunek V, Eurin D, Lévêque C, Hellot M, Bénichou J: Magnesium sulphate given before verypreterm birth to protect infant brain: the randomised controlled PREMAG trial. BJOG 2007, I | 4:3 I 0-8.

50. Rouse DJ, Hirtz DG, Thom E, Varner MW, Spong CY, Mercer BM, lams JD, Wapner RJ, Sorokin Y, Alexander JM, Harper M, Thorp JM, Ramin SM, Malone FD, Carpenter M, Miodovnik M, Moawad A, O'Sullivan MJ, Peaceman AM, Hankins GDV, Langer O, Caritis SN, Roberts JM: A randomized, controlled trial of magnesium sulfate for the prevention of cerebral palsy. N Engl J Med 2008, 359:895-905.

FIOOOPrime

5I. Costantine MM, Weiner SJ: Effects of antenatal exposure to magnesium sulfate on neuroprotection and mortality in preterm infants: a meta-analysis. Obstet Gynecol 2009, I I 4:354-64.

\section{FlOOOPrime

RECOMMENDED

52. Conde-Agudelo A, Romero R: Antenatal magnesium sulfate for the prevention of cerebral palsy in preterm infants less than 34 weeks' gestation: a systematic review and metaanalysis. Am J Obstet Gynecol 2009, 200:595-609.

\section{FIOOOPRime
RECOMMENDED}

53. Doyle LW, Crowther CA, Middleton P, Marret S, Rouse D: Magnesium sulphate for women at risk of preterm birth for neuroprotection of the fetus. Cochrane Database Syst Rev 2009, CD004661.

FIOOOPrime

54. Royal College of Obstetricians and Gynaecologists: Scientific Impact Paper 29: Magnesium Sulphate to Prevent Cerebral Palsy following Preterm Birth. RCOG $201 \mathrm{I}$.

55. Research Centre for Health of Women and Babies: Antenatal magnesium sulphate prior to preterm birth for neuroprotection of the fetus, infant and child: National Clinical Practice Guidelines. Adelaide: The University of Adelaide, ARCH 2010. [http://www.adelaide.edu.au/ arch]

56. American College of Obstetricians and Gynecologists Committee on Obstetric Practice; Society for Maternal-Fetal Medicine: Committee Opinion No. 573: Magnesium sulfate use in obstetrics. Obstet Gynecol 2013, I22:727-8.

\section{FlOOOPrime}

\section{RECOMMENDED}

57. Doyle LW, Anderson PJ, Haslam R, Lee KJ, Crowther C; Australasian Collaborative Trial of Magnesium Sulphate (ACTOMgSO4) Study Group: School-age outcomes of very preterm infants after antenatal treatment with magnesium sulfate vs placebo. JAMA 2014, 312:1105-13. 